\title{
Connective tissue growth factor induces hepatic progenitor cells to differentiate into hepatocytes
}

\author{
AI-TING YANG, PING WANG, XIAO-FEI TONG, MIN CONG, TIAN-HUI LIU, \\ RUI CONG, PENG WU, JI-DONG JIA, BAO-EN WANG and HONG YOU \\ Liver Research Center, Beijing Friendship Hospital, Capital Medical University, Beijing, P.R. China
}

Received January 15, 2013; Accepted April 5, 2013

DOI: $10.3892 /$ ijmm.2013.1380

\begin{abstract}
Connective tissue growth factor (CTGF) plays an important role in the proliferation of hepatic progenitors, however, little is known concerning the mechanism(s) through which it influences their differentiation. The differentiation of hepatic progenitors (WB-F344), either stimulated with recombinant CTGF or stably transfected with a CTGF overexpression plasmid, was investigated. Expression of the differentiation markers $\alpha$-fetoprotein (AFP), albumin (ALB) and cytokeratin-19(CK-19) was assessed. To confirm the effects of CTGF on progenitor differentiation, cells were treated with an inhibitor (WP631) of CTGF. Treatment of WB-F344 cells with recombinant CTGF for $24 \mathrm{~h}$ did not change the survival rate significantly, but the progenitors were enlarged with a decreased nuclear/cytoplasmic ratio. CTGF downregulated the expression of the fetal hepatocyte marker, AFP, while it upregulated the mature hepatocyte cell marker, ALB. The effect of CTGF overexpression plasmid on WB-F344 cell differentiation was consistent with a pattern of direct CTGF stimulation, including decreased AFP and increased ALB expression. Furthermore, the suppression of CTGF induction by an inhibitor was associated with significant inhibition of hepatic progenitor cell differentiation into hepatocytes. Importantly, we showed that differentiated WB-F344 cells by CTGF had in vitro functions characteristic of hepatocytes, including ALB production, glycogen storage and cytochrome P450 activity. Both recombinant CTGF and the CTGF overexpression plasmid induced hepatic progenitor differentiation into hepatocytes. This was suppressed by the CTGF inhibitor.
\end{abstract}

\section{Introduction}

Under conditions of severe liver injury, or inhibited hepatocyte proliferation, undifferentiated hepatic progenitor/stem cells

Correspondence to: Professor Hong You or Professor Bao-En Wang, Liver Research Center, Beijing Friendship Hospital, Capital Medical University, Beijing 100050, P.R. China

E-mail: youhong30@sina.com

E-mail: wangbbee@126.com

Key words: connective tissue growth factor, hepatic progenitor cell, differentiation, hepatocyte are activated to mediate liver regeneration $(1,2)$. Progenitor cells are activated via various signaling and growth factors (2). In humans, proliferating progenitor cells are observed during chronic liver disease, and the degree of hepatic progenitor cell activation corresponds with the severity of liver fibrosis and inflammation (3-6). Therefore, it is necessary to understand the mechanisms underlying progenitor activation and differentiation during chronic liver disease.

Connective tissue growth factor (CTGF) is a cysteine-rich protein secreted via a 37-amino acid signal sequence. CTGF is an important mediator of liver fibrosis and its overexpression correlates with the progression of hepatic fibrosis (7-9). CTGF also plays an important role in progenitor activation during liver regeneration triggered by $2-\mathrm{N}$-acetylaminofluorene/ partial hepatectomy (2-AAF/PHx) (10-12). Previous studies conducted in our laboratory showed that transforming growth factor- $\beta 1$ (TGF- $\beta 1$ ) inhibits the viability of rat progenitors in a dose-dependent manner and alters their phenotype (13). Being a downstream mediator of TGF- $\beta 1$, CTGF may prove to be an important factor, governing cell differentiation and regeneration during tissue repair.

To investigate this possibility, we examined the influence of CTGF on the differentiation of hepatic progenitor cells in vitro, using WB-F344 cells as a model for rat hepatic progenitor cells $(14,15)$. WB-F344 cells are characterized by a high nuclear to cytoplasmic ratio, and they express markers characteristic of both hepatocytes $[\alpha$-fetoprotein (AFP) and albumin (ALB)] and cholangiocytes [cytokeratin-19 (CK-19)]. These cells retain the ability to differentiate into either hepatocytes or cholangiocytes under the appropriate conditions $(14,16,17)$.

\section{Materials and methods}

Cell culture. WB-F344 cells were plated in Dulbecco's modified Eagle's medium (DMEM) supplemented with $10 \%(\mathrm{v} / \mathrm{v})$ fetal bovine serum (FBS) (both from Gibco, Grand Island, NY, USA) (complete medium). When the cells were 80-90\% confluent, they were detached using trypsin and reseeded at a density of $1 \times 10^{5}$ cells $/ \mathrm{ml}$ in $100-\mathrm{mm}$ dishes. WB-F344 cells were cultured overnight in serum-free medium prior to the experiments. Cells were either stimulated, or not stimulated, with different concentrations of CTGF ( 1 or $5 \mathrm{ng} / \mathrm{ml}$; PeproTech, Rocky Hill, NJ, USA), a CTGF inhibitor (WP631, $0.01 \mathrm{nM}$; 
Table I. Primers used for reverse transcription polymerase chain reaction.

\begin{tabular}{llccc}
\hline Gene & \multicolumn{1}{c}{ Primer sequences } & $\begin{array}{c}\text { Product } \\
\text { size (bp) }\end{array}$ & Accession no. & $\begin{array}{c}\text { Annealing } \\
\text { temperature }\end{array}$ \\
\hline CTGF & $\begin{array}{l}\text { F: 5'-ACCATGCTCGCCTCCGTC-3' } \\
\text { R: 5'-GCTTTACGCCATGTCTCCATAC-3' }\end{array}$ & 1050 & NM_022266 & $58^{\circ} \mathrm{C}$ \\
\multirow{2}{*}{ GAPDH } & $\begin{array}{l}\text { F: 5'-ATGGCCTTCCGTGTTCCTAC-3' } \\
\text { R: 5'-TTACTCCTTGGAGGCCATGT-3' }\end{array}$ & 318 & BC059110 & $58^{\circ} \mathrm{C}$ \\
& & & & \\
\hline
\end{tabular}

CTGF, connective tissue growth factor; GAPDH, glyceraldehyde 3-phosphate dehydrogenase.

Table II. Antibodies and conditions for western blot analysis.

\begin{tabular}{lllcll}
\hline $\begin{array}{l}\text { Primary } \\
\text { antibody }\end{array}$ & Type & Host & $\begin{array}{c}\text { Total proteins } \\
(\mu \mathrm{g})\end{array}$ & $\begin{array}{c}\text { Working } \\
\text { dilution }\end{array}$ & Source \\
\hline AFP & Monoclonal & Mouse & 20 & $1: 1,000$ & R\&D MAB1368 \\
CK-19 & Monoclonal & Mouse & 20 & $1: 1,000$ & R\&D MAB3506 \\
ALB & Monoclonal & Mouse & 20 & $1: 1,000$ & R\&D MAB1455 \\
CTGF & Polyclonal & Rabbit & 20 & $1: 500$ & Abcam ab5097 \\
$\beta$-actin & Monoclonal & Mouse & 20 & $1: 4,000$ & Sigma-Aldrich A1978 \\
\hline
\end{tabular}

AFP, $\alpha$-fetoprotein; CK-19, cytokeratin-19; ALB, albumin; CTGF, connective tissue growth factor.

Alexis Biochemical, San Diego, CA, USA) and cultured for $24 \mathrm{~h}$. Total mRNA and proteins were then extracted.

Cell viability. WB-F344 cells (6,000 cells/well) were seeded into 96-well plates and treated with CTGF or WP631 as described above. A cell viability assay was performed using 3-(4,5-dimethylthiazol-2-yl)-2,5-diphenyltetrazolium bromide (MTT). Three duplicate wells were used for each sample. Twenty microliters of MTT $(5 \mathrm{mg} / \mathrm{ml})$ was added to each well and incubated for $4 \mathrm{~h}$. The supernatant was then removed and $150 \mu 1$ DMSO was added to dissolve the formazan crystals. Plates were then transferred to a plate reader and the absorbance was measured at $450 \mathrm{~nm}$.

Quantitative real-time PCR analysis of differentiation marker expression. Quantitative real-time PCR was performed using an ABI PRISM 7300 Sequence Detection (Applied Biosystems, Foster City, CA, USA) and the ABI Power SYBR-Green PCR Master Mix kit (Applied Biosystems, Warrington, UK). The primers used for amplification (Table I) were designed to be between 60 and $150 \mathrm{bp}$ in length according to the PE Applied Biosystems guidelines for the comparative $\mathrm{C}_{\mathrm{T}}$ method. A final primer concentration of $300 \mathrm{nM}$ was assessed as the optimum for use under all conditions to ensure that no nonspecific amplification occurred in the sample wells. RT was carried out for $2 \mathrm{~min}$ at $5^{\circ} \mathrm{C}$ before incubation for $10 \mathrm{~min}$ at $95^{\circ} \mathrm{C}$ to inactivate the reverse transcriptase, which otherwise interferes with the DNA polymerase. Forty cycles at $95^{\circ} \mathrm{C}$ for $15 \mathrm{sec}$ followed by $60^{\circ} \mathrm{C}$ for $60 \mathrm{sec}$ were performed, and the fluorescence was measured at the end of each extension cycle. A SYBR-Green dissociation curve was constructed at the end of the reaction to ensure specificity; the temperature was increased from 65 to $95^{\circ} \mathrm{C}$ in $0.1^{\circ} \mathrm{C} / \mathrm{sec}$ increments, and the fluorescence signals were measured and plotted against the temperature. The amount of target, normalized to an endogenous reference [glyceraldehyde 3-phosphate dehydrogenase (GAPDH)] and relative to a calibrator (WB-F344 cells cultured untreated), was given by the formula $2^{-\Delta \Delta \mathrm{C} t}$, as determined by the ABI PRISM 7300 System Software's (Applied Biosystems) built-in algorithm using an adaptive baseline to determine the $\mathrm{Ct}$. The relative amounts were expressed as the means \pm SD from three independent experiments.

Differentiation marker expression assessed by western blotting. Total proteins were extracted using a cellular protein extraction solution, and protein concentrations were measured using the BCA protein assay (Pierce, Rockford, IL, USA). After boiling for $10 \mathrm{~min}$, the lysates were separated on $12 \%$ SDS-PAGE gels. Proteins were transferred to nitrocellulose membranes (Amersham Biosciences, Piscataway, NJ, USA), which were blocked in TTBS containing 5\% non-fat dried milk for $2 \mathrm{~h}$ at room temperature. The membranes were then incubated with anti-ALB, anti-AFP, anti-CK-19 (all from R\&D System, USA) and anti-CTGF (Abcam, Hong Kong, China) primary antibodies (Table II) at $4^{\circ} \mathrm{C}$ overnight. After three washes, the membranes were incubated with the corresponding horseradish peroxidase-conjugated rabbit anti-mouse or goat anti-rabbit secondary antibodies (diluted 1:8,000 and 1:9,000, respectively) for $1 \mathrm{~h}$. The membranes were then subjected to chemiluminescence (Pierce Chemical Co.) detection and fluorography using X-ray film. After signal detection, the membranes were re-incubated with an anti- $\beta$-actin antibody 
Table III. Primers used for real-time polymerase chain reaction.

\begin{tabular}{|c|c|c|c|}
\hline Gene & Primer sequences & Product size (bp) & Accession no. \\
\hline AFP & $\begin{array}{l}\text { F: 5'-GGAGAAGTGCTGCAAAGACC-3' } \\
\text { R: 5'-TTGTCCTTTCTTCCTCCTGG-3' }\end{array}$ & 120 & NM_012493 \\
\hline ALB & $\begin{array}{l}\text { F: 5'-AGAACCAGGCCACTATCTC-3' } \\
\text { R: 5'-CAGATCGGCAGGAATGTTGT-3' }\end{array}$ & 110 & NM_134326 \\
\hline CK-19 & $\begin{array}{l}\text { F: 5'-CAGCAGTATTGAAGTCCAGC-3' } \\
\text { R: 5'-TCAAGCAGGCTTCGGTAGGT-3' }\end{array}$ & 139 & NM_199498 \\
\hline GAPDH & $\begin{array}{l}\text { F: 5'-CCTGCCAAGTATGATGACATCAAGA-3' } \\
\text { R: 5'-GTAGCCCAGGATGCCCTTTAGT-3' }\end{array}$ & 75 & ВC059110 \\
\hline
\end{tabular}

AFP, $\alpha$-fetoprotein; ALB, albumin; CK-19, cytokeratin-19; GAPDH, glyceraldehyde 3-phosphate dehydrogenase.

(Sigma-Aldrich, St. Louis, MO, USA) as a loading control. The experiment was performed three times.

Periodic acid-schiff (PAS) staining. Cells were fixed by $4 \%$ paraformaldehyde for $30 \mathrm{~min}$ and then washed with $\mathrm{dH}_{2} \mathrm{O}$. They were then oxidized in $0.5 \%$ periodic acid for $15 \mathrm{~min}$ at room temperature, rinsed in $\mathrm{dH}_{2} \mathrm{O}$ for 1 min and treated with Schiff's reagent (Sigma-Aldrich) for $30 \mathrm{~min}$ at room temperature. After rinsing in $\mathrm{dH}_{2} \mathrm{O}$ for $2 \mathrm{~min}$, counterstaining was performed with haematoxylin for $2 \mathrm{~min}$, rinsed in running tap water and observed under an inverted microscope.

Determination of medium levels of albumin and cytochrome P450. Medium levels of albumin and cytochrome P450 were determined using an albumin enzyme-linked immunosorbent assay system and cytochrome P450 enzyme-linked immunosorbent assay system (both from Blue Gene, China) according to the instructions supplied by the manufacturer.

Construction of full-length CTGF gene plasmids. Full-length CTGF was amplified from the cDNA of WB-F344 cells using the forward, 5'-atagatctgaccatgctcgcctccgtcg-3' (BglII site italicized) and the reverse primer, 5'-atctcgagctttacgccatgtctcc ata-3' (XhoI site italicized). This fragment was inserted into the $B g l \mathrm{II}$ and $X h o$ I sites of the vector, dl6-95/neo to yield the recombinant plasmid, d16-95/CTGF/neo. The recombinant plasmids were amplified in competitive cells, purified using a Wizard ${ }^{\circledR}$ Plus SV Miniprep DNA Purification System (Promega) and verified by DNA sequencing.

Establishment of the stably transfected WB-F344 cell line and identification. Prior to the transfection experiments, monolayers were trypsinized and the cells were plated $1 \times 10^{5}$ cells/well in a 6 -well format. After overnight culture, cells were $60-70 \%$ confluent. The cells were divided into three groups: a WB-F344 cell control group; a d16-95/neo group and a d16-95/CTGF/neo group, and transfected with plasmid DNA using FuGene ${ }^{\circledR}$ HD transfection reagent ( $9 \mu 1$ transfection reagent to $3 \mathrm{~g}$ DNA; Roche, Mannheim, Germany) according to the manufacturer's protocol. The medium was replaced with medium containing $10 \%$ FBS after 8 h of transfection. Forty-eight hours later, cells were trypsinized, plated in $2 \times 100-m m$ dishes, and cultured overnight. The medium was then replaced with fresh complete medium containing $\mathrm{G} 418(100 \mu \mathrm{g} / \mathrm{ml})$ for the stable transfection experiments. The medium was replaced every 3-5 days. Cells were incubated for 20 days, during which the G418 killed all the control cells, and the d16-95/neo and d16-95/CTGF/neo groups developed stable clones. The medium was then replaced with medium containing $50 \mu \mathrm{g} / \mathrm{ml} \mathrm{G} 418$ for continued culture until total mRNA or proteins were extracted. The expression of CTGF mRNA was detected by reverse transcription-polymerase chain reaction. The sequences of the primers used for PCR are shown in Table III. The PCR conditions were: 30 cycles at $94^{\circ} \mathrm{C}$ for $40 \mathrm{sec}$, annealing for $40 \mathrm{sec}$ (temperature shown in Table I) and $72^{\circ} \mathrm{C}$ for $60 \mathrm{sec}$. Hepatic stellate cells were used as a control. PCR products were analyzed by electrophoresis on $1 \%$ agarose gels.

Statistical analysis. Data are expressed as means \pm SD from three independent experiments. Differences between mean values of multiple groups were analyzed using the nonparametric ANOVA test (SPSS, Inc., Chicago, IL, USA). Comparison between 2 groups was made using the Student's t-test. $\mathrm{P}<0.05$ was indicative of a statistically significant result.

\section{Results}

Effect of recombinant CTGF on viability and morphology of WB-F344 cells. WB-F344 cells were treated with different doses of rCTGF $(0.5,1,2,4,8$ or $16 \mathrm{ng} / \mathrm{ml})$, resulting in cell viabilities of 99, 99, 95, 97, 95 and 91\%, respectively, after $24 \mathrm{~h}$ of incubation. The percentage of viable cells gradually decreased to $91,91,88,83,73$ and $56 \%$, respectively, after $48 \mathrm{~h}$ of incubation (Fig. 1A). To determine the dose which had the lowest effect on progenitor proliferation, we selected doses of 1 and $5 \mathrm{ng} / \mathrm{ml} \mathrm{CTGF}$ and a treatment time of $24 \mathrm{~h}$.

Cultured WB-F344 cells were small and polygonal with a high nuclear/cytoplasmic ratio. After treatment with CTGF ( $5 \mathrm{ng} / \mathrm{ml}$ ) for $24 \mathrm{~h}$, the cells were enlarged and the nuclear/ cytoplasmic ratio was decreased (Fig. 1B).

Recombinant CTGF induces the differentiation of WB-F344 cells into hepatocytes. The WB-F344 cell line is an in vitro 
A

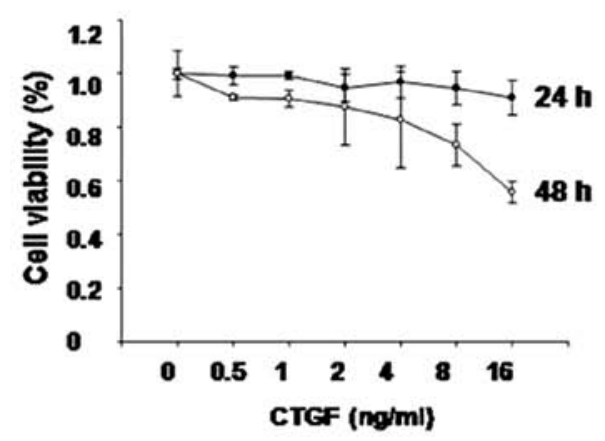

B
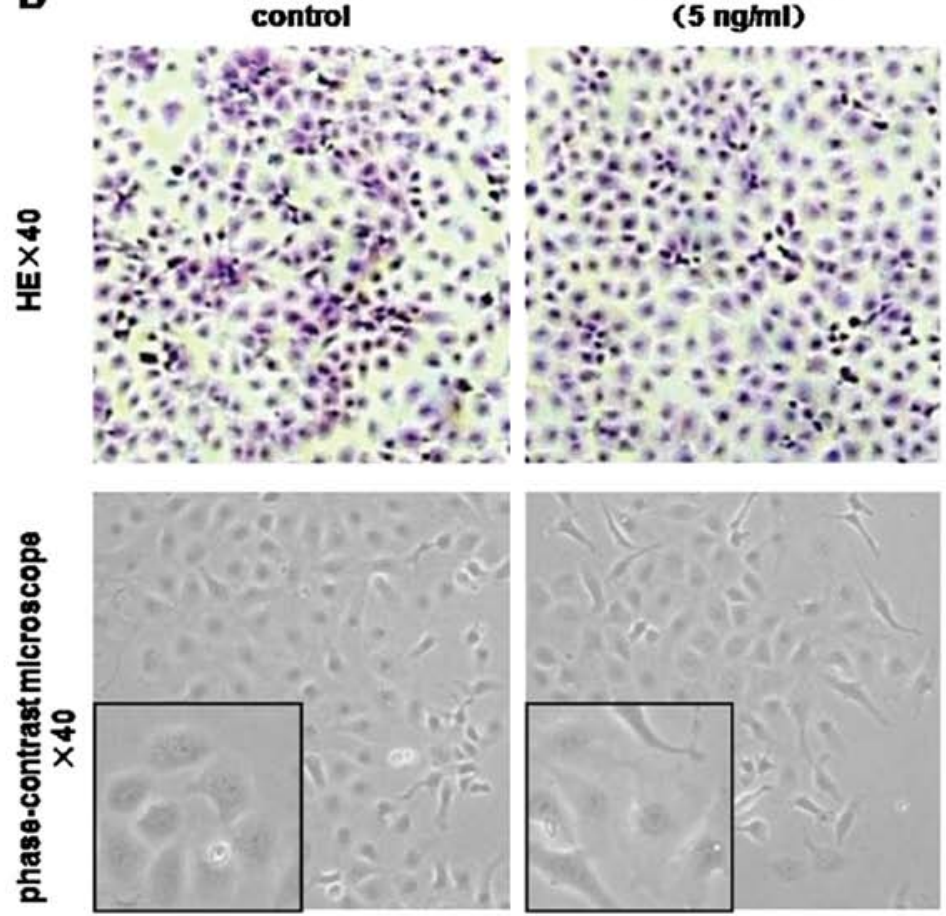

WBF344+CTGF

$(5 \mathrm{ng} / \mathrm{ml})$

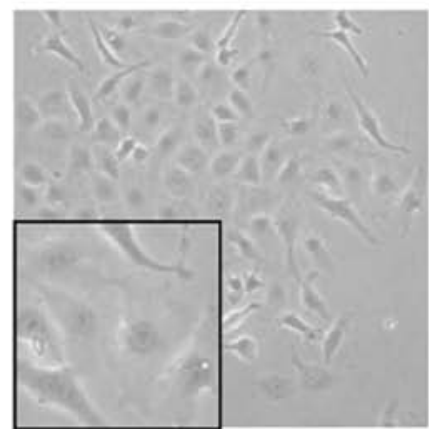

Figure 1. Influence of CTGF on the cell viability and morphology of WB-F344 cells. (A) Treatment of WB-F344 cells with recombinant CTGF for $24 \mathrm{~h}$ did not significantly change the survival rate, while culturing for $48 \mathrm{~h}$ with CTGF inhibited the survival rate in a dose-dependent manner. (B) After CTGF treatment, WB-F344 cells were enlarged and the nuclear/cytoplasmic ratio was decreased.
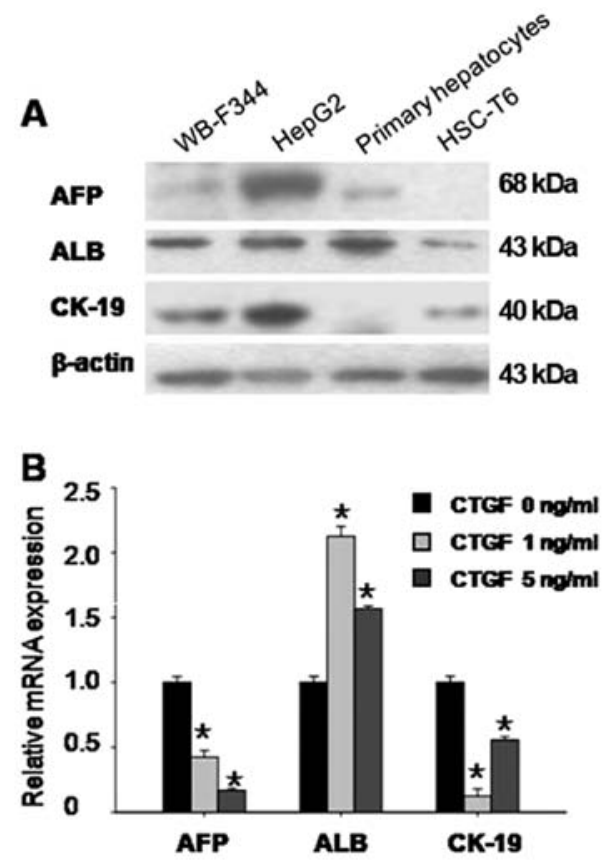
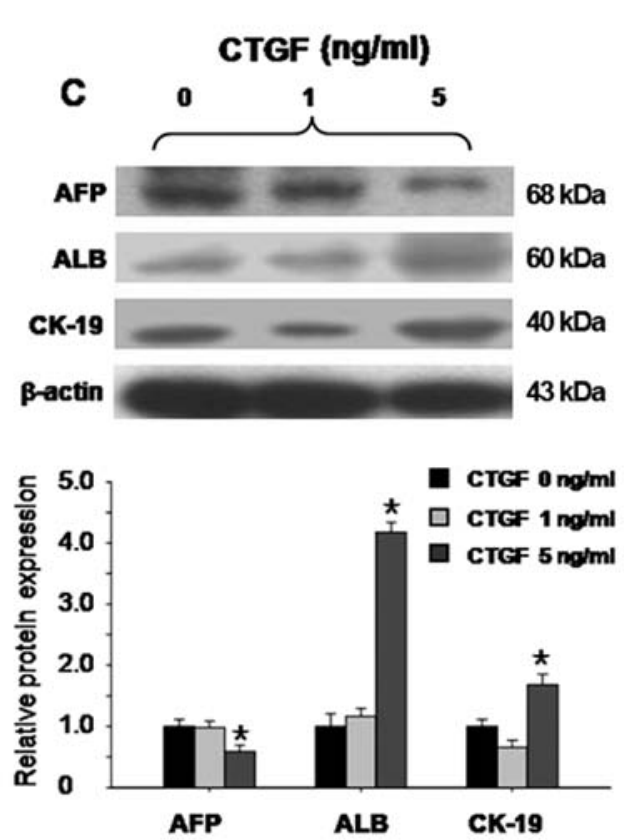

Figure 2. Effects of CTGF on WB-F344 cell differentiation. (A) WB-F344 cells share both hepatocyte markers (AFP, ALB) and cholangiocyte marker (CK-19). HepG2, rat primary hepatocytes, and hepatic stellate cells were used as the control. (B) Levels of progenitor markers were altered in the WB-F344 cells, following stimulation by CTGF for $24 \mathrm{~h}$. High dose $(5 \mathrm{ng} / \mathrm{ml})$ CTGF decreased AFP mRNA expression, increased ALB mRNA expression and decreased CK-19 mRNA expression. (C) High dose (5 ng/ml) CTGF also altered the expression of the hepatic progenitor cell markers at the protein level, with decreased AFP expression and increased ALB and CK-19 expression. Quantification and normalization are shown in the bottom panel. Data are expressed as the means \pm SD from three independent experiments. ${ }^{*} \mathrm{P}<0.05$ compared with CTGF at $0 \mathrm{ng} / \mathrm{ml}$. AFP, $\alpha$-fetoprotein; ALB, albumin.

model of hepatic progenitor cells. These progenitors express both AFP and ALB, which are hepatocyte markers, highly expressed either in the liver carcinoma cell line HepG2 or in primary isolated rat hepatocytes. WB-F344 cells also express CK-19, which is a cholangiocyte marker, also highly expressed by HepG2 cells (Fig. 2A). 

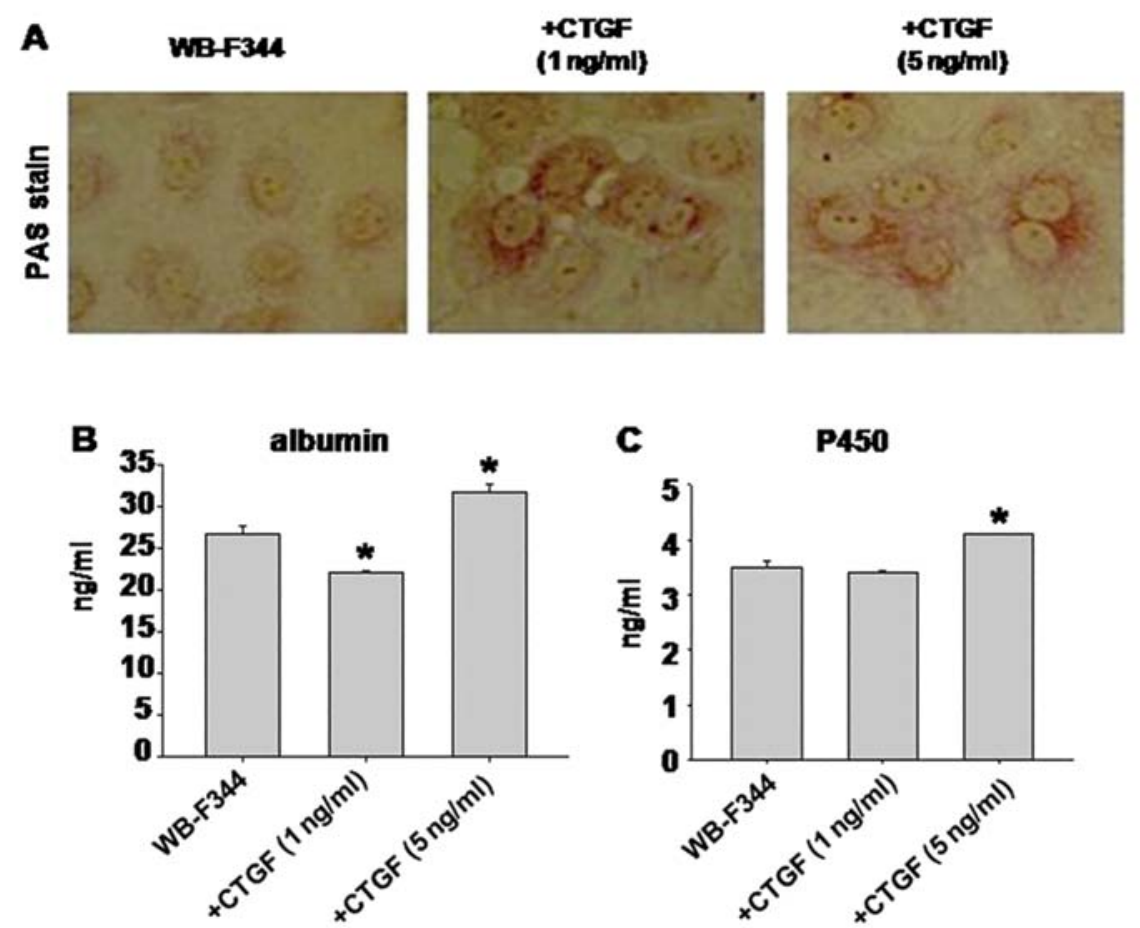

Figure 3. In vitro functional characterization of hepatocytes differentiated from WB-F344 cells. WB-F344 cells were stimulated with different concentrations of CTGF (1 and $5 \mathrm{ng} / \mathrm{ml}$ ) for $24 \mathrm{~h}$. (A) Glucose storage as indicated by periodic acid Schiff (PAS) staining. (B) Albumin secretion and (C) CYP450 activity. All data are shown as means \pm SD from 3 independent experiments. $\mathrm{P}<0.05$ compared with WB-F344 control cells.

To study whether CTGF alters the expression of the hepatic progenitor cell markers to induce differentiation, we observed changes in their expression levels after CTGF treatment. Treatment with CTGF at $5 \mathrm{ng} / \mathrm{ml}$ in serum-free medium for $24 \mathrm{~h}$ resulted in a 0.2 -fold decrease in the AFP mRNA level, a 1.6-fold increase in the ALB mRNA level and a 0.6-fold decrease in the CK-19 mRNA level (in all $\mathrm{P}<0.05$ ) (Fig. 2B). This was accompanied by a 0.6 -fold decrease in AFP protein levels, a 3.5-fold increase in the ALB protein level, and a 1.6-fold increase in the CK-19 protein level, respectively (in all $\mathrm{P}<0.05$ ) (Fig. 2C). CTGF at $1 \mathrm{ng} / \mathrm{ml}$ caused only minor changes in the expression levels of the hepatic progenitor markers at the protein level. These results indicate that recombinant CTGF induces WB-F344 cell differentiation into hepatocytes rather than cholangiocytes.

Finally, to confirm whether the differentiated cells exhibit the functional properties of hepatocytes, we examined the specific function of hepatocytes, including glycogen storage, albumin production and cytochrome $\mathrm{P} 450$ production. WB-F344 cells stimulated with CTGF gained the capability of glycogen storage (Fig. 3A), which was absent in cells without CTGF. These results were in correlation with the albumin (Fig. 3B) and cytochrome P450 (Fig. 3C) production.

Inhibition of CTGF suppresses WB-F344 cell differentiation . To further investigate the role of CTGF in the differentiation of hepatic progenitor cells, we focused on whether a chemical inhibitor that blocks CTGF expression suppresses the differentiation of WB-F344 cells. A chemical inhibitor of CTGF (WP631) was used.

We first determined the optimal concentration of WP631 by an MTT assay. Treatment with WP631 at $\geq 0.5 \mathrm{nM}$ for 24 or
$48 \mathrm{~h}$ reduced cell viability. Thus, we selected $0.1 \mathrm{nM}$ WP631 for the subsequent experiments, which resulted in cell viability of $90 \%$ after $24 \mathrm{~h}$ (Fig. 4A), without significantly affecting WB-F344 cell morphology (Fig. 4B).

WB-F344 cells were incubated with the inhibitor for $24 \mathrm{~h}$ (preliminary time-response experiments indicated that this afforded maximal inhibition of CTGF expression; data not shown). Incubation with $0.1 \mathrm{nM}$ WP631 in serum-free medium decreased CTGF expression 0.4-fold ( $\mathrm{P}<0.05)$ (Fig. 4C).

Finally, we examined whether inhibition of CTGF affects WB-F344 cell differentiation towards hepatocytes. Treatment with $0.1 \mathrm{nM}$ WP631 decreased ABL expression 0.6-fold $(\mathrm{P}<0.05)$, but increased AFP expression 2.1-fold $(\mathrm{P}<0.05)$ (Fig. 4D).

Endogenous CTGF induces WB-F344 cell differentiation. We next examined whether endogenous CTGF also induces the differentiation of WB-F344 cells. We isolated CTGF cDNA from WB-F344 cells and constructed a plasmid carrying the full-length CTGF gene (details in 'Materials and methods') (Fig. 5A). WB-F344 cells were transfected with the CTGF plasmid (d16-95/CTGF/neo) or a blank plasmid (d16-95/neo) using the FuGene HD reagent (Fig. 5D). Following the selection of clones in medium containing G418, the expression of CTGF by stably transfected WB-F344 cells was analyzed by PCR and western blotting. The expression of CTGF mRNA and protein was increased in WB-F344 cells transfected with the CTGF plasmid when compared with that in the control (Fig. 5B and C).

After stable transfection, endogenous CTGF also altered the phenotype of hepatic progenitor cells. The expression of AFP decreased in the d16-95/CTGF/neo group (0.7-fold; 


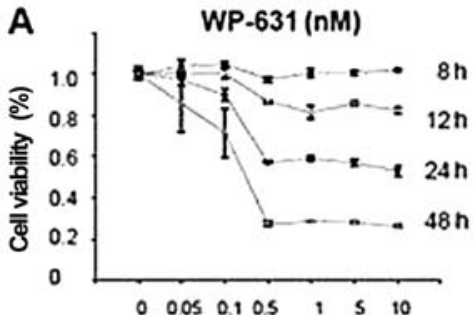

C
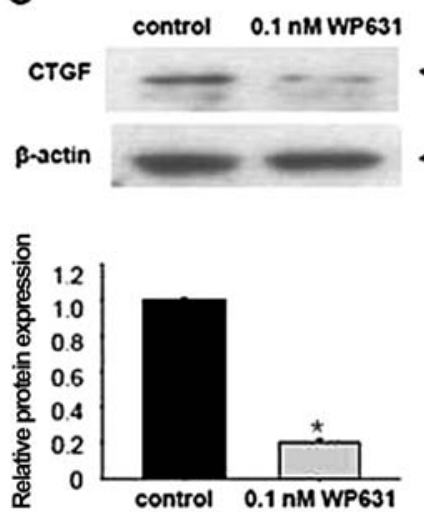

B
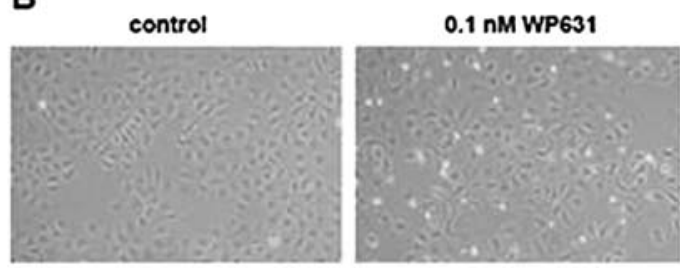

phase-contrast microscope $\times 40$

D
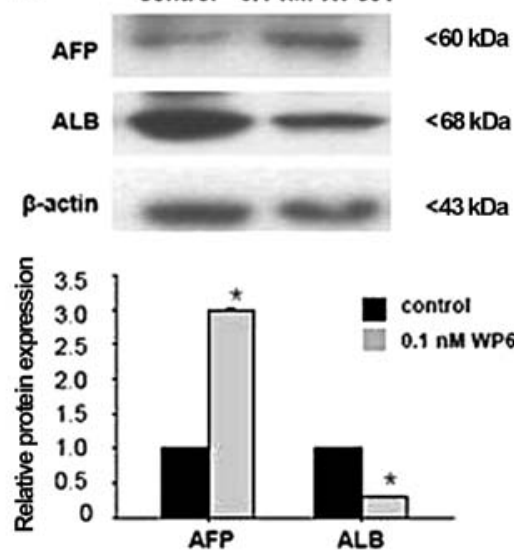

Figure 4. Influence of the CTGF inhibitor on WB-F344 cell viability and differentiation. (A) After incubation of cells for 8, 12, 24 and $48 \mathrm{~h}$ with various concentrations of WP631 (0-10 nM), cell viability was inhibited in a time-dependent and a dose-dependent manner. (B) WP631 (nM) did not significantly change the morphology of WB-F344 cells. (C) Expression of CTGF was significantly inhibited by WP631. Quantification and normalization are shown in the bottom panel. (D) After suppressing CTGF expression, AFP was upregulated, while ALB was downregulated. Data are expressed as the means \pm SD from three independent experiments. "P<0.05 compared with control. AFP, $\alpha$-fetoprotein; ALB, albumin.

A

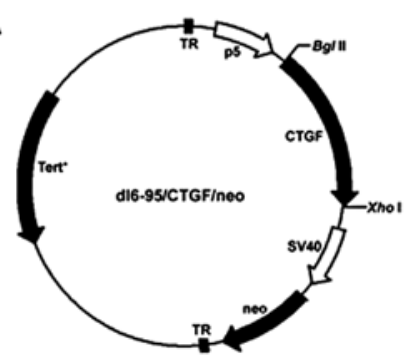

D

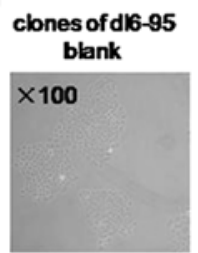

clones of di6-95 CTGF

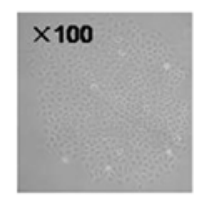

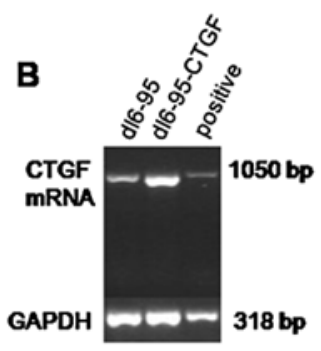

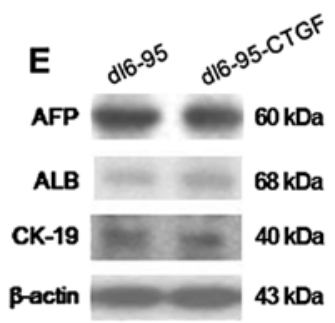

C

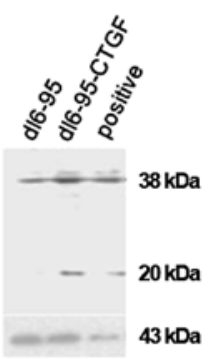

Bactin $=-43 \mathrm{kDa}$

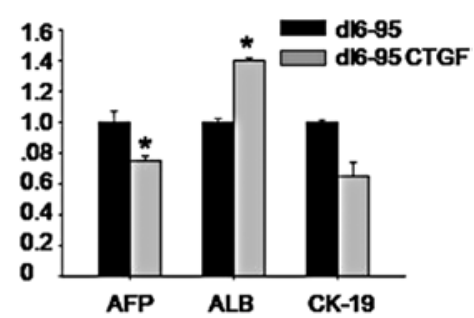

Figure 5. Endogenous CTGF alters the phenotype of hepatic progenitor cells. (A) The plasmid carrying the full-length CTGF gene was constructed. (B and C) The expression of CTGF by stably transfected WB-F344 cells was analyzed. CTGF was increased significantly in WB-F344 cells after transfection with the d16-95/CTGF/neo plasmid compared with that in the d16-95/neo group. (D) G418-resistant clones were selected after stable transfection. (E) Levels of the progenitior markers were significantly altered, including decreased AFP and increased ALB expression, while CK-19 did not change. Quantification and normalization are shown in the right panel. All data are expressed as the means \pm SD from three independent experiments. "P<0.05 compared with the d16-95-blank group. AFP, $\alpha$-fetoprotein; CK-19, cytokeratin-19; ALB, albumin.

$\mathrm{P}<0.05$ ) when compared with the dl6-95/neo group. In contrast, expression of the mature hepatocyte maker, ALB, increased (1.4-fold compared with the blank plasmid; P<0.05). CK-19 expression did not change significantly ( $\mathrm{P}>0.05)$ (Fig. 5E). Endogenous CTGF stimulated WB-F344 cell differentiation to a lesser degree than recombinant CTGF. 


\section{Discussion}

Progenitor cell-mediated liver regeneration is a complex process, involving sequential waves of cytokine secretion and remodeling of the extracellular matrix (ECM) $(2,18)$. CTGF, a TGF- $\beta$ downstream mediator, is involved in many biological processes, such as cell adhesion, proliferation, survival, migration and angiogenesis $(8,19,20)$. CTGF may also be involved in liver regeneration, since a TGF- $\beta 1$ responsive element is present in the promoter region of the CTGF gene $(21,22)$. Studies have shown that CTGF expression increases during liver regeneration occurring after $2 \mathrm{AFF} / \mathrm{PH}$ and GalN administration in rats (10-12). Taken together, these data indicate that CTGF may play an important role in progenitor activity during the liver regeneration phase. However, there is no direct evidence showing that CTGF affects progenitor differentiation.

The results of the present study indicate that CTGF induces the differentiation of hepatic progenitor cells into hepatocytes in vitro. Both stimulation by recombinant CTGF and overexpression of CTGF induced WB-F344 cells to differentiate into hepatocytes. CTGF increased the expression of a mature hepatocyte marker (albumin) and decreased that of a fetal hepatocyte marker (AFP). Importantly, WB-F344 cells acquired hepatocyte-specific functions upon treatment with CTGF resulting in albumin production, cytochrome P450 and glycogen storage ability

However, induction of WB-F344 cell differentiation using recombinant CTGF was greater than that noted with endogenous CTGF. CTGF, a secreted protein, acts via both autocrine and paracrine cellular circuits to regulate functions such as cell proliferation, growth and cell differentiation $(7,23)$; therefore, under certain conditions, CTGF induced by TGF- $\beta$, vascular endothelial growth factor (VEGF), platelet derived growth factor (PDGF), endothelin-1 or hypoxia may play a role in differentiation (24).

To further investigate the role of CTGF during the differentiation of WB-F344 cells, we used an inhibitor of CTGF. According to previous studies, WP631 is able to suppress CTGF expression (7,24).

WP631 (dimethanesulfonate) was found to inhibit Spl-initiated transcription and was effective in reducing CTGF expression (25). Sp-1, one of several general transcription factor-binding sites, is thought to be present in the promoter region of the CTGF gene $(20,22)$. In our study, WP631 was very potent at inhibiting CTGF expression in WB-F344 cells and impaired WB-F344 cell differentiation into hepatocytes.

Numerous studies have shown that CTGF plays a crucial role in the fibrotic remodeling of various organs, and it has frequently been proposed as a therapeutic target for the management of fibrotic disorders $(9,21)$. However, little is known concerning its physiological function. In this study, we found that CTGF induced the differentiation of WB-F344 cells into hepatocytes in vitro. It has been reported that the degree of hepatic progenitor cell activation corresponds with the severity of liver fibrosis and inflammation $(5,19)$. CTGF is overexpressed in fibrotic lesions and the degree of overexpression correlates with the severity of fibrosis $(9,19)$. Also, activation of hepatic stellate cells is required for an appropriate oval cell response to differentiation $(4,6,17)$. As mentioned above, the ability of CTGF to induce the differentiation of hepatic progenitor cells and promote liver regeneration during fibrosis requires further investigation.

\section{Acknowledgements}

This study was supported by the National Natural Science Foundation of China (81270519 and 81100294), the Program for New Century Excellent Talents in the University (NCET09-0008) and the Beijing Health System Talents Plan (2009-3-06).

\section{References}

1. Michalopoulos GK: Liver regeneration after partial hepatectomy: critical analysis of mechanistic dilemmas. Am J Pathol 176: 2-13, 2010.

2. Fausto N, Campbell JS and Riehle KJ: Liver regeneration. Hepatology 43: S45-S53, 2006.

3. Bird TG, Lorenzini S and Forbes SJ: Activation of stem cells in hepatic diseases. Cell Tissue Res 1: 283-300, 2008.

4. Pintilie DG, Shupe TD, Oh SH, et al: Hepatic stellate cells' involvement in progenitor-mediated liver regeneration. Lab Invest 90: 1199-1208, 2010

5. Zheng ZY, Weng SY and Yu Y: Signal molecule-mediated hepatic cell communication during liver regeneration. World $\mathbf{J}$ Gastroenterol 15: 5776-5783, 2009.

6. Roskams T: Relationships among stellate cell activation, progenitor cells, and hepatic regeneration. Clin Liver Dis 12: 853-860, 2008.

7. Gressner OA and Gressner AM: Connective tissue growth factor: a fibrogenic master switch in fibrotic liver diseases. Liver Int 28: 1065-1079, 2008

8. Tong Z, Chen R, Alt DS, et al: Susceptibility to liver fibrosis in mice expressing a connective tissue growth factor transgene in hepatocytes. Hepatology 50: 939-947, 2009.

9. Chen L, Charrier AL, Leask A, et al: Ethanol-stimulated differentiated functions of human or mouse hepatic stellate cells are mediated by connective tissue growth factor. J Hepatol 55: 399-406, 2011.

10. Pi L, Oh SH, Shupe T and Petersen BE: Role of connective tissue grow th factor in oval cell response during liver regeneration after 2-AAF/PHx in rats. Gastroenterology 128: 2077-2088, 2005.

11. Ujike K, Shinji T, Hirasaki S, et al: Kinetics of expression of connective tissue growth factor gene during liver regeneration after partial hepatectomy and D-galactosamine-induced liver injury in rats. Biochem Biophys Res Commun 277: 448-454, 2000.

12. Pi L, Ding X, Jorgensen M, et al: Connective tissue growth factor with a novel fibronectin binding site promotes cell adhesion and migration during rat oval cell activation. Hepatology 47: 996-1004, 2008.

13. Wang P, Liu T, Cong M, et al: Expression of extracellular matrix genes in cultured hepatic oval cells: an origin of hepatic stellate cells through transforming growth factor beta? Liver Int 29: 575-584, 2009.

14. Lázaro CA, Rhim JA, Yamada Y and Fausto N: Generation of hepatocytes from oval cell precursors in culture. Cancer Res 58: 5514-5522, 1998.

15. Snykers S, De Kock J, Rogiers V and Vanhaecke T: In vitro differentiation of embryonic and adult stem cells into hepatocytes: state of the art. Stem Cells 27: 577-605, 2009.

16. Shiojiri N, Lemire JM and Fausto N: Cell lineages and oval cell progenitors in rat liver development. Cancer Res 51: 2611-2620, 1991.

17. Nagai H, Terada K, Watanabe G, et al: Differentiation of liver epithelial (stem-like) cells into hepatocytes induced by coculture with hepatic stellate cells. Biochem Biophys Res Commun 293: 1420-1425, 2002

18. Duncan AW, Dorrell C and Grompe M: Stem cells and liver regeneration. Gastroenterology 137: 466-481, 2009.

19. Blom IE, Goldschmeding R and Leask A: Gene regulation of connective tissue growth factor: new targets for antifibrotic therapy? Matrix Biol 21: 473-482, 2002. 
20. Gressner OA, Weiskirchen R and Gressner AM: Evolving concepts of liver fibrogenesis provide new diagnostic and therapeutic options. Comp Hepatol 6: 7, 2007.

21. Holmes A, Abraham DJ, Chen Y, et al: Constitutive connective tissue growth factor expression in scleroderma fibroblasts is dependent on Sp1. J Biol Chem 278: 41728-41733, 2003.

22. Grotendorst GR, Okochi $\mathrm{H}$ and Hayashi N: A novel transforming growth factor beta response element controls the expression of the connective tissue growth factor gene. Cell Growth Differ 7: 469-480, 1996.

23. Tan JT, McLennan SV, Song WW, et al: Connective tissue growth factor inhibits adipocyte differentiation. Am J Physiol Cell Physiol 295: C740-C751, 2008.
24. Leask A, Parapuram SK, Shi-Wen X and Abraham DJ: Connective tissue growth factor (CTGF, CCN2) gene regulation: a potent clinical bio-marker of fibroproliferative disease? J Cell Commun Signal 3: 89-94, 2009.

25. Gressner OA, Lahme B, Demirci I, et al: Differential effects of TGF-beta on connective tissue growth factor (CTGF/CCN2) expression in hepatic stellate cells and hepatocytes. J Hepatol 47: 699-710, 2007. 